Vol. 3, No. 2, 2016

UDC 658.1

Z. Skybinska,

$\mathrm{PhD}$ in Economics, Associate Professor

T. Hryniv

$\mathrm{PhD}$ in Economics, Associate Professor

Lviv Polytechnic National University

\title{
ECONOMIC ANALYSIS: HISTORY OF DEVELOPMENT AND MAJOR COMPONENTS
}

\begin{abstract}
In the article, the authors investigate the history of economic analysis and the interpretations of economic analysis; define its subject and object, and other major components. The major tasks and directions of economic analysis are described. The classification of factors in the economic analysis and the reserves for increasing production efficiency is done. The major principles of economic analysis are generalized. The place of economic analysis in the system of sciences is identified.
\end{abstract}

Keywords: economic analysis, factors in economic analysis, reserves for increase in production efficiency, tasks of economic analysis, principles of economic analysis.

\section{Introduction}

The study of the phenomena of nature and public life is impossible without their analysis. The term "analysis" originates from Greek "analysis", which is translated as "decomposition", "dismemberment". Thus, an analysis in the narrow understanding is dismemberment of a phenomenon or an object into component parts (elements) for their study. It helps "glance" into the inside of the explored phenomenon, process, understand its internal essence, and determine the role of every element in the object or phenomenon. For instance, to understand the essence of the production cost, it is necessary to know not only of what elements it is composed, but also what determines its size for each item of expenditure. The more the cost increase is differentiated by elements and factors, the more we learn about the economic phenomenon and more effectively we will be able to manage the process of cost formation.

The phenomena and processes of environment can not be understood only by their analysis. Very often the need to use other methods comes up. The synthesis, most closely associated with the analysis, is a method of studying the subject in its integrity, identifying relationships and dependences between different parts of the explored subject. Analysis and synthesis are interconnected and interdependent in their unity; provide the scientific study of phenomena in multilateral dialectical relation.

Transition from the analysis of facts to the synthesis is carried out by induction (a way of transition from knowledge of separate facts to the knowledge of the whole, from the study of causes to effects) and deduction (a way of research from general to partial, from effects to causes).

An analysis and synthesis, induction and deduction, as the general methods of cognition make the base of economic analysis.

\section{The basic tasks and directions of economic analysis}

Economic analysis, as a scientific discipline, is the system of special skills, related to research of economic processes and complexes, rates, proportions, as well as progress trends, with the exposure of their deep essence and reasons, which predetermine different deviations from the planned indicators, contractual obligations, and with the objective estimation of their implementation.

Every science has the subject of research, which it studies with the proper purpose by its peculiar methods. Determination of the subject is of principle value for independence substantiation of any field of knowledge.

The subject of economic analysis includes:

- economic processes which occur as a result of economic and financial activities;

- causal connections, which determine the use of all types of resources and outcomes of the activities; 
- reserves and the ways to increase the efficiency and to strengthen the competitiveness of enterprises.

Only by setting causal relationship of various sides of activity, it is possible to calculate quickly how basic results of economic activity will change due to this or that factor, to substantiate any managerial decision, to foresee changes in the profit value, break-even sales, financial stability, unit cost in case any production situation changes.

Objects of analysis, unlike subject, - are separate economic phenomena, processes, problems, questions, indicators. All objects of analysis in complex make the subject of economic analysis. Among objects of analysis, for example, there can be production and commercial activity, presence and use of material, labor and financial resources, products quality and profit, rhythm of production, financial results of production, financial state of enterprise and the like.

The purpose of economic analysis is:

1) to provide proper estimation of object's state and show how it differs from the planned state;

2) to identify opportunities and ways to bring the object from the actual state to the proper one;

3) to determine the size and nature of reserves to increase efficiency;

4) to prepare materials for choosing optimal production operational management decisions and to plan the further economic activities on the basis of the identified reserves.

In institutions of non-production sectors (health, education etc.) analysis is conducted to assess the national economic, economic and social effect that is achieved as a result of the activities as well as to estimate these institutions' compliance with costs saving and the expenditures on their maintenance.

The basic tasks of economic analysis are:

1) estimation of the enterprise economic activities and implementation of the plan;

2) identification of positive and negative factors influencing the enterprise activities;

3 ) control over the process of implementing the plan, as well as over reality and validity of the plan;

4) identification of unused reserves to improve the product quality, increase production and sales, as well as speed up the turnover of working capital;

5) control over production austerity and efficiency.

Among the major directions of economic analysis there are:

- theory of economic analysis; analysis);

- business analysis (financial and managerial

- analysis by economic activities;

- strategic analysis (Fig. 1).

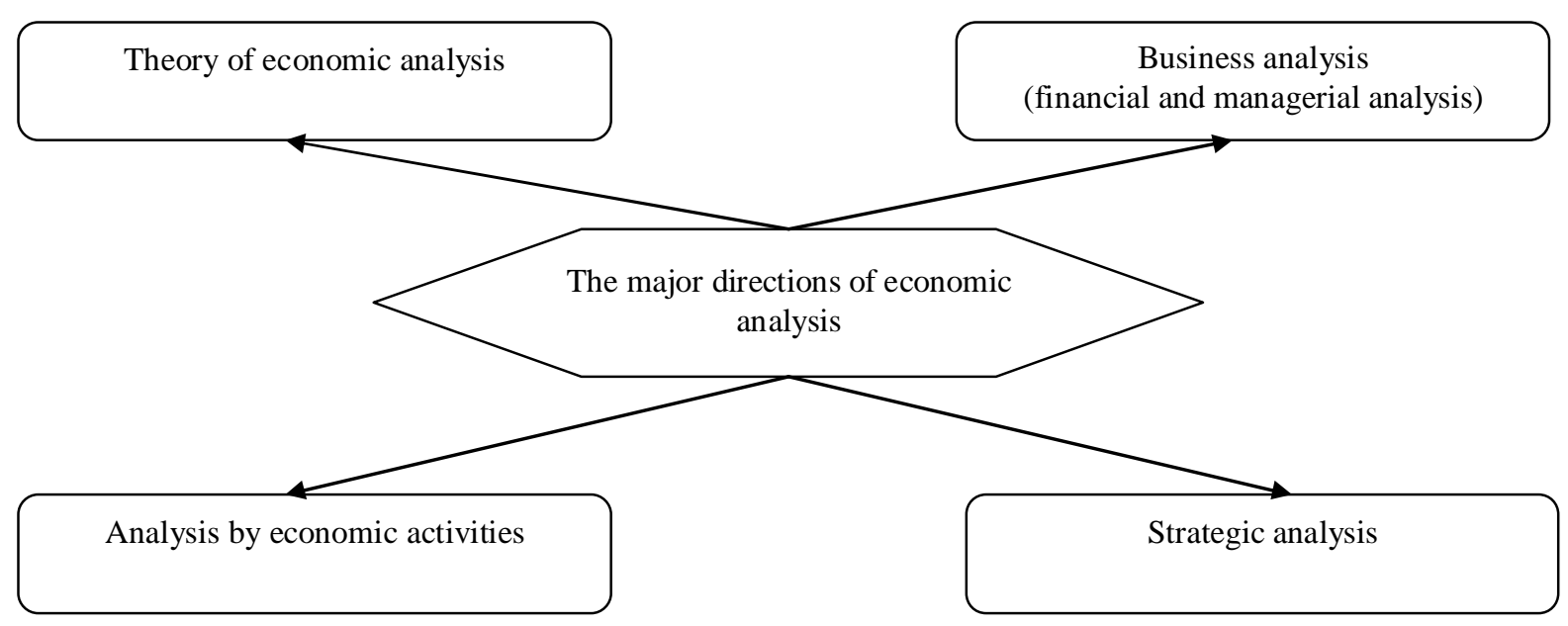

Fig. 1. The major directions of economic analysis

The theory of economic analysis is an integral component of economic analysis as a science, which is a set of generalized scientific statements (a system of principles, ideas) that summarize the practical experience and reflect laws of economic phenomena and processes in an analytical context.

Analysis of economic activities is an economic analysis of enterprise activities results, in which there is conducted a comprehensive 
estimation of their compliance to the aim and objectives set. Such an analysis is an essential element of management. Its aim is to identify the value of economic indicators characterizing production, consumption of products, goods and services, resource efficiency, quality of manufactured products and see how these indicators are changing over time. During the analysis there are identified causes and possible effects of the factors that are observed and studied.

Strategic analysis is a comprehensive study of internal resources and capabilities of enterprises aimed at evaluating the future state of business, its strengths and weaknesses.

\section{The establishment and development of the analysis of economic activities}

It is necessary to distinguish between general theoretical economic analysis, which examines economic phenomena and processes at macro level, and specifically economic analysis at micro level, i.e. analysis of economic activities, which is used to study the economics of individual enterprises.

Formation of the analysis of economic activities was caused by general objective requirements and conditions that accompany the emergence of any new field of knowledge. Firstly, this is satisfaction of a practical need. An intuitional analysis, approximate calculations and considerations are insufficient for large production units. Without complex comprehensive analysis of economic activities it is impossible to manage complicated economic processes and make optimal decisions. Secondly, it is related to the development of economic science in general. As it is known, development of any science leads to differentiation of its branches.

Analysis of economic activities was formed as a result of differentiation of social sciences. Earlier the functions of economic analysis (when they were not so considerable) were performed within the limits of the then existing scientific disciplines, such as record-keeping, accounting, finances, and statistics. Later the first simplest tools of analytical research appeared.

The founder of systematized analysis as a component of bookkeeping is considered to be Jacques Sapary (1622-1690), though the use of some elements of economic analysis was observed in other countries, including Italy, at the same time. Thus Angelo Di Pietro promoted the methodology of comparison of budget allocations to actual expenses; Bastian Venturi analyzed dynamic series of indicators of the economic entity for ten years.

In the late XIX - early XX century there was gradually formed the original direction in accounting - that of balance studies. There was also actively developing the science of business (financial) calculations, which became the basis of financial analysis.

In the history of establishment and development of business analysis as a science such stages are distinguished: pre-revolutionary (1917), the post-revolutionary period, the period of transition to market economy.

Before the revolution, business analysis consisted mainly in analyzing and assessing the balance of assets and liabilities. There did not exist any specialized literature or unified schemes of economic analysis; there were used just brief instructions for commercial banks on how to check the creditworthiness of customers.

After 1917 economic analysis developed in accordance with various phases of socialist economy and the needs of the administrativecommand system. The development of methods of analysis originally was due to the necessity of evaluating the accounting records. For a long time the development of methods of analysis was carried out by specialists in accounting and the first and sometimes the only practical workers who conducted the analysis of enterprises were the most experienced accountants. At that time there was analyzed only the company's balance sheet, and hence the first name of the course was "Analysis of the balance". Later, when the volume of reporting expanded, and thus, the amount of data increased and significantly changed the content of the information that was studied, the course got the title "Accounting Analysis". Thus we can assume that analysis comes from bookkeeping or "accounting". During the period of New Economic Policy, enterprises transferred to the principles of self-sufficiency, and therefore there appeared the desire to study and analyze the consequences of their economic activities; there was actively carried out analytical work on economic activities of consumer cooperatives. The need for implementing economic analysis in practice of industrial enterprises defined the course on industrialization of enterprises. Hard work on adjustment of accounting and control necessarily resulted into the 
elaboration of special methods of studying accounting quality and business activities outcomes, being often based on summary reports of enterprises.

In the 30s analysis was introduced to the curricula of universities of the USSR in the form of the final section of the course "Accounting". There were printed the first textbooks and manuals (by N. R. Weizmann, S. K. Tatour, M. I. Bakanov and others) concerning analysis of balance. These books had methodological nature and therefore they can be considered to be the beginning of business analysis. It was just in the 30s that analysis established as a science. This was due to the following reasons: liquidation of the capital market, centralization of the banking system and liquidation of the real independence of enterprises. All this resulted in weakening the role of commercial calculations. The preference was given to the analysis of deviations of the actual indicators from the planned ones. The role of the balance sheet as a tool of financial management was reduced; the control function of analysis was strengthened.

In the 40 s, they began to use normative, planned, technical and other types of information for performing analysis. The course got the titles "Technical economic analysis", "Analysis of economic activities", and finally, "Economic analysis". It was widely used in practice with the purpose of carrying on complex systems studies of the enterprise economics and finding resources to increase production. In future the role of economic analysis grew in accordance with the cost of error in performing economic activities.

The post-revolutionary period can be characterized as a period of thorough development of theoretical analysis. A special significance is given to analyzing individual sectors of the economy, studying the work of self-supporting enterprises and their divisions, developing methods of analysis of consolidated reports. Gradually there are developed independent areas of economic analysis, such as comparative, technical, economic, operational, economic and mathematical, functional and cost analysis and others. A great work has been done to develop the economic analysis and improve its methods, prepare the basic provisions for the implementation of economic analysis in the transition to market conditions.

Now economic analysis can be described as the science being sufficiently developed theoretically but at the same time being in the state of constant development. Research is conducted in relation to more wide application of mathematical methods, computers, which allow optimizing administrative decisions. Theoretical achievements of national and foreign science are being implemented in practice.

The prospects of economic analysis development in theoretical direction are closely associated with the development of related sciences, first of all, mathematics, statistics, recordkeeping and others. Besides, the analysis development depends on the requests from practice. As to the perspectives of its practical application, analysis of economic activities is gradually becoming the key factor in the management system of any enterprise.

With the transition to market economy economic analysis is gaining importance at all levels of production. Using economic analysis it is possible to solve economic, organizational problems, make managerial decisions such as strategic decisions concerning planning and tactical decisions in operational management of the production process. Such analysis has an active character, as managerial decisions concern a particular economic entity and are aimed at improving the efficiency of its economic activities.

\section{Factors' classification in economic analysis}

Any production depends on its provision with appropriate resources. Their prudent use is an everyday anxiety and duty of every enterprise. Reducing unit cost of resources per unit of output contributes to social production efficiency, improves all indicators of manufacturers.

There are many types of resources. Among them there are natural, production, intellectual, financial, currency resources and others. For a production such classification of resources is suitable: labor resources, basic labor facilities and tools. An important production resource is space (land area) and time. Resources can be initial (natural) and derivative (artificial). Derivative resources include commodity, informative, financial, scientific and other resources.

In the process of production resources begin to interact with each other. Such interactions take the form of factors.

A factor is a motive force of any process or phenomenon, which determines their character and 
result. Otherwise speaking, a factor is a cause, which brings certain effect (consequence). In production many causal relations (factors) are formed, and consequently, their identification, measurement and study constitute an important task of economic analysis.

Factors are classified according certain features (Table 1).

\section{Factors' classification in economic analysis}

\begin{tabular}{|l|l|}
\hline \multicolumn{1}{|c|}{ The feature of classification } & \multicolumn{1}{c|}{ Factors' types (groups) } \\
\hline The degree of influence on work results & primary and secondary \\
\hline Places of origin & external and internal \\
\hline $\begin{array}{l}\text { The degree of dependence on the activities of } \\
\text { individuals and legal entities }\end{array}$ & objective and subjective \\
\hline Time & permanent and temporary \\
\hline The nature of the impact & extensive and intensive \\
\hline Level of coverage & general and specific \\
\hline Internal content & quantitative and qualitative \\
\hline The level of detailing & simple and complex \\
\hline The level of subordination & of the first, second,... $\mathrm{n}$-th order \\
\hline
\end{tabular}

Primary are those factors that affect the results of the enterprise and secondary do not significantly affect the enterprise performance.

External and internal factors are the factors that depend and do not depend on the enterprise activities.

Objective factors are independent of the will and desires of the people, while subjective factors depend on the activities of businesses and individuals.

Permanent factors influence the phenomenon continuously during all the time. The impact of temporary factors appears periodically (new technology, development of new technology).

Extensive factors are related to the quantitative growth of the effective indicator, such as increasing production volume by increasing the number of workers, the number of days worked, duration of shifts. Intensive factors characterize the degree of effort, labor intensity in the production process, such as increased productivity, return on assets and others.

General factors are those which take place throughout the economy. Specific factors are operating in terms of only one sector of the economy or business.

Quantitative factors measure the quantitative characteristics of phenomena, and qualitative ones determine the internal quality features of the objects studied.

Complex factors, as opposed to simple, consist of several elements.
In terms of the factors' impact on economic phenomenon or process (level of subordination) there are distinguished factors of the first, second and ... $\mathrm{n}$-th order. The factors of the first order are those that directly affect the effective indicator. All other factors affect the effective indicator indirectly, through factors of a higher level.

A factor always has not only a size but also a direction of action. That is why there are distinguished positive and negative factors. The last factor is often associated with production reserves. Thus appears one more definition: a factor is a predecessor of production reserves.

\section{Reserves for increase in production efficiency}

Under the influence of labor or power factors production resources begin to move, interact and, eventually, they transform into new things material wealth, products. But part of the resources remains unused or is used inefficiently, lost, deteriorated and accumulated as wastes, is evaporated, weathered or dissolved in water. In this connection there turns out the issue of production reserves.

While studying this category it is necessary to realize that the concept "reserve" has two different definitions.

1. Reserve is a stock of resources, which is not used consciously and is supported at certain level as a means, which provides reliability and continuity of operation of any system. 
2. Reserve is an unused or lost opportunity of something, for example, growth of production, improvement of products quality, profitability increase and so on.

In the first definition reserve characterizes any reserve stock. Remember currency reserves of the National Bank (stocks), insurance and reserve funds of the country and enterprises, standby power grids etc.

The second understanding of reserve is associated, first of all, with different losses of resources (spoilage, loss, shortage, and depreciation), fines and penalties payments as well as other losses. Those are obvious, unquestionable reserves. However, there are such reserves, which are predetermined by the increase of resources consumption norms, payroll over-expenditure and so on. Some reserves are irrecoverable losses of resources or profits, others can be used in the next periods of time. Classification of reserves is presented in Table 2.

Table 2

\section{Classification of reserves to increase production efficiency}

\begin{tabular}{|c|c|}
\hline Features of grouping & Types of reserves \\
\hline $\begin{array}{l}\text { By sources of improving production efficiency (factors } \\
\text { of the labor process) }\end{array}$ & $\begin{array}{l}\text { - labour reserves } \\
\text { - reserves of using labor facilities } \\
\text { - reserves of using labor tools (material resources) }\end{array}$ \\
\hline By place of emergence (sources of formation) & $\begin{aligned} &- \text { external } \\
&, \text { industry } \\
&, \text { regional } \\
&, \quad \text { nationwide } \\
& \text { - internal } \\
&\end{aligned}$ \\
\hline By the nature of impact on the results of activities & $\begin{array}{l}\text { - extensive } \\
\text { - intensive }\end{array}$ \\
\hline By final results, which are affected by reserves & $\begin{array}{l}\text { - increasing the volume of production; } \\
\text { - improving the structure and assortment of products; } \\
\text { - improving product quality; } \\
\text { - declining the unit cost by cost elements, by items of } \\
\text { expenditure, by centers of responsibility; } \\
\text { - improving production profitability; } \\
\text { - strengthening financial position and increasing } \\
\text { profitability. }\end{array}$ \\
\hline By product life cycle stages & $\begin{array}{l}\text { - pre-production stage } \\
\text { - manufacturing stage } \\
\text { - operational stage (exploitation) } \\
\text { - stage of product recycling }\end{array}$ \\
\hline By period of use & $\begin{array}{l}\text { - current } \\
\text { - perspective }\end{array}$ \\
\hline By means of detection & $\begin{array}{l}\text { - obvious } \\
\text { - hidden }\end{array}$ \\
\hline
\end{tabular}

The main feature of classification of production reserves is classification by sources of improving production efficiency, which embrace three main groups (simple moments of the labor process): purposeful activity, or work itself, the subject of labor and the means of labor. By this feature, there are differentiated three groups: material resources reserves, production reserves, and labor reserves.

From the position of the company, depending on the places of emergence (sources of formation) they distinguish external and internal reserves. Depending on the level of management, external reserves are divided into industry, regional, and nationwide. The use of external reserves affects the level of enterprise economic indicators, but the main source of savings for enterprises is, as a rule, internal production reserves.

By the nature of impact on the results of enterprise activities reserves are divided into extensive and intensive. Extensive reserves include those, the implementation of which requires involving additional resources. Intensive reserves are considered to be most fully associated with 
complete and rational use of the production possibilities of the company.

Reserves are also classified by final results, which they affect. There are distinguished the following reserves: of increase of production output; improvement of the structure and assortment of products; product quality improvement; reduction of unit cost by cost elements, by items of expenditure, by responsibility centers; improvement of production profitability; strengthening of financial position and increase of the level of profitability.

For rational organization of reserves' search a great value has their grouping by stages of reproduction process (supply, production and sales), as well as by stages of creation and usage of products, i.e. the product life cycle (pre-production stage - design and technological preparation of production; manufacturing stage - development of a new product and new technologies in production; operational stage (exploitation) - consumption of a product, utilization stage -removal of a product from manufacture).

On the basis of the period of use reserves are divided into current (implemented during a year) and perspective (which can be realized in the longer term).

By means of detection reserves are classified into obvious (liquidation of obvious losses and cost overruns) and hidden, which can be detected by a deep economic analysis, its particular methods, such as inter-economic comparative analysis, function-value analysis and others.

In the process of calculating reserves it is necessary to consider the following rules:

1) reserves should count only the negative impact of factors that may be affected by the company;

2) during calculation of production output increase reserves:

- from one moment of work (use of the objects of labor, means and efficiency of labor) there is calculated the total reserve;

- from all three moments of labor there is calculated a complete reserve, that is the smallest of three groups of reserves, provided with all kinds of resources.

The company should reinforce all identified reserves with the necessary means that allow these reserves' mobilization and implementation into practical activities.

\section{Basic principles of economic analysis}

Analytical research, its results and their application in production management should meet certain requirements. These requirements have their impact on the course of analysis and must be obligatory met during analytical research design, organization, conduction and practical use of analysis results. Major principles of analysis are presented in Fig. 2.

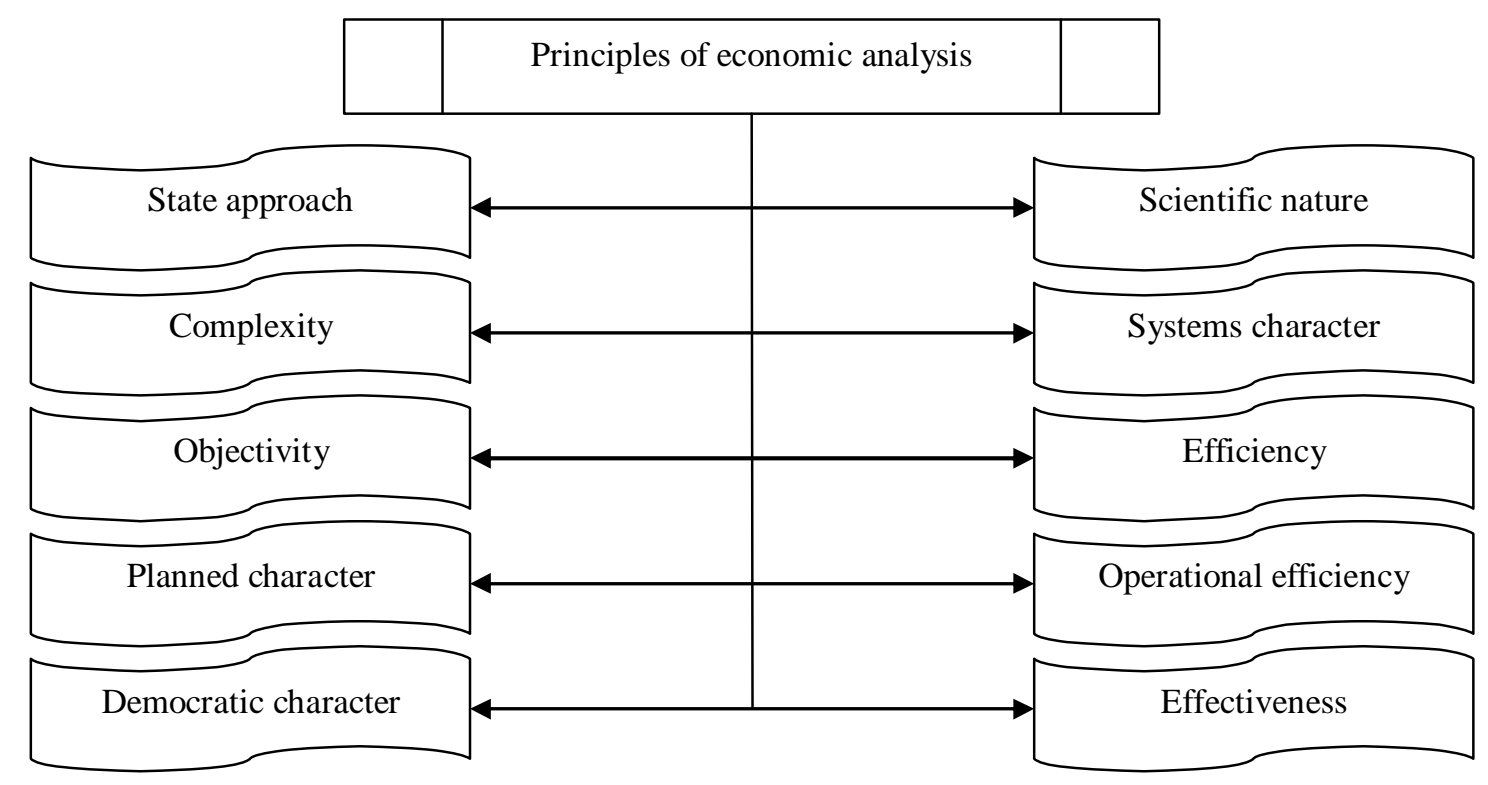

Fig. 2. Principles of economic analysis

State approach consists in estimation of certain events of economic life with the account of the state economic, social, ecological, international policies and current legislation. 
The principle of scientific nature is based on the ideas of dialectical theory of cognition, takes into account the requirements of economic laws of production development, and draws on scientific achievements, as well as innovative progressive methods of economic research.

A complexity includes maximum structural subdivisions and directions of activity. It comprehensively studies causal dependences in organization development.

The systems character consists in the fact that an object which is studied is examined as a difficult dynamic system, which contains elements, linked between themselves and with an external environment. All internal and external links must be taken into account, as well as interdependence and inter-subordination of certain elements.

Objectivity is based on the verified information which reliably shows the objective reality. Conclusions must be substantiated by exact analytical calculations. This requires the permanent improvement of the organization' accounting system, systems of audit, revision and control, as well as methods of analysis to increase accuracy and reliability of calculations.

Effectiveness implies the ability to impact actively on the results of production, to identify shortcomings in time and promptly inform the enterprises management about them. This principle induces practical use of analysis results in the system of enterprises management for developing concrete measures on substantiation and correction of the planned figures.

Planned character implies conducting analysis according to a plan, systematically and regularly. This causes the necessity of analytical work planning in the organization, distribution of duties between executors and control after its conducting.

Operational efficiency is the ability to quickly and accurately conduct the analysis of situations, make proper managerial decisions and implement them at the enterprise.

Democratic character foresees participating of a wide range of workers in conducting analysis, provides a comprehensive study of good practices and the use of internal economic reserves.

The efficiency is based on the fact that the cost of performing analysis should be appropriate, timely, and give a multiple effect.

These principles must be observed in performing economic analysis at any level of management.

\section{Conclusions and prospects for further research}

Economic analysis was formed at the intersection of many sciences by integrating some of their elements. This formation occurred following the urgent need for enhanced scientific development of issues associated with the necessity to clarify the impact of an increasing number of reasons and factors that determine the effectiveness of economic entity activities in market conditions and competition. First of all, a direct connection of economic analysis with the development of other economic sciences, particularly, economic theory should be emphasized. The laws of economic development formulated by this science form the theoretical basis of economic analysis. Since the general laws of economic development differently manifest themselves in individual industries, the analysis of their economic activities should be based on the industrial economy. And as a consequence, economic analysis is connected with the economics of industry, agriculture, construction, transport and so on. Economic analysis is very closely linked with accounting and statistics. Materials of accounting, tax, managerial, statistical reporting, sample observations are the information base for the analysis of economic phenomena and processes occurring in the enterprise.

Statistical techniques and methods of economic information processing are very widely used in analysis as a statistical science develops methods for groupings, indices, correlation, regression and so on, essentially updates the arsenal of analytical methods and techniques.

Economic analysis is closely related to the audit. The audit cannot be considered an effective tool of studying activities of economic entities, if inspection and audit of economic activities do not include elements of analysis. Analysis and forecasting of the financial conditions of the company, its profitability, and financial stability should be considered as the ultimate goal of the audit.

Economic analysis makes extensive use of mathematical science achievements; the ability to picture a particular economic phenomenon using economic and mathematical models of economic analysis opens up endless possibilities for improving techniques, methods and tools of analysis and organizing analytical work.

Economic analysis is related to management due to the necessity to make managerial decisions. Taking optimal managerial decisions has turned 
into a major problem nowadays. Economists are developing the theory of managerial decisionmaking, which is one of the sections of management science. Decision-making theory should account multiple choices, uncertainty and influence of factors on every single option. In these conditions economic analysis is urgently needed.

Marketing and economic analysis imply the analysis of macro and microenvironments, opportunities, competitors, market prices, market conditions and as a result, the development of marketing programs.

Financial and credit disciplines also have a connection with the economic analysis. This connection implies applying methodical principles of analysis to studying financial possibilities, the ways of strengthening financial position, justifying the amounts of loans to be taken etc. In market conditions such a connection is a necessity.

Thus economic analysis is a synthetic science, which was formed on the basis of differentiation and integration of many sciences.

With the help of economic analysis it is possible to check whether planned assignments are substantiated, whether all the possibilities to improve the enterprise economic activities by increasing production capacity, labor productivity have been used, i.e. whether the plan is intense enough. Using economic analysis it is possible to identify the unused possibilities of increasing efficiency of the enterprise economic activities rising production and sales volumes, cutting prime costs, improving financial results and financial state of the enterprise.

An economic analysis is directed toward the improvement of performance of enterprises yet at the stage of developing plans, when the intensity of planned tasks is estimated. At the same time, economic analysis allows controlling plans fulfillment by the enterprise as a whole and by its structural units - shops, sites, teams etc.; it helps discover drawbacks and identify the contribution of every unit into the overall results.

In the process of analysis the level of responsibility of every worker for economical use of resources is determined. Production, financial and investment activities are analyzed, that allows identifying factors, which influence all directions of enterprise activities.

An economic analysis is based on the objective estimation of the use of resources which an enterprise uses for achieving the best financial results with minimum expenses. It allows defining real production possibilities of an enterprise, its scientific and technical potential, as well as the ways to mobilize the identified resources for work improvement. Besides, economic analysis helps to quickly adapt to the changing market environment, to predict possible changes of partners' behavior, to avoid unnecessary economic risk.

\section{References}

1. Andreeva G. I. Economic analysis: textbook / G. I. Andreeva. - K. : Znannia, 2008. - 263 p. (Series "Higher education XXI century").

2. Bulativ A. S. Economic analysis of business activity: manual / A. S. Bulativ. - K. : Znannia, 2007. $-408 p$.

3. Kindratska G. I. Economic analysis: textbook / G. I. Kindratska and others -3 th edition, remake and expanded - K. : Znannia, 2008. $-487 p$.

4. Kozak I. I. Economic analysis: textbook for students of institution of higher education / I. I. Kozak. - Lviv Regional Institute of Public Administration of National Academy of Public Administration of the President of Ukraine. - 2-th edition. - L. : LRIPANAPA, 2010. - 217 p.

5. Kosova T. D. Organization and methodology of economic analysis: textbook / T. D. Kosova, P. M. Suharev, L. O. Vashchenko, I. V. Grechyna, N.E. Deeva. - K. : Center of educational literature, 2012. $-528 \mathrm{p}$.

6. Lazaryshyna I. D. Methodology and organization of economic analysis : textbook /I. D. Lazaryshyna. / Ukrainian State University of Water Management and Environmental Sciences. - Rivne : USUWMES, 2004. - $112 p$.

7. Mnyh E. V. Economic analysis of business activity / E. V. Mnyh, Kyiv National Trade and Economic University. $-K, 2008$.

8. Sopko V. V. Organization of accounting, economic monitoring and analysis: textbook / V. V. Sopko, V. P. Zavgorodnij / Kyiv National Economic University. - K. : KNEU, 2004. $-411 p$. 